\title{
La educación ambiental en el nivel primaria: plan y programas de estudio, acciones y Covid-19
}

\section{Environmental education in elementary school: curricula, actions, and COVID-19}

DOI: https://doi.org/10.32870/dse.v0i24.985

Karen Liliana Jaimes Martínez*

\begin{abstract}
Resumen
La educación ambiental ha surgido con fuerza desde finales del siglo XX como un paradigma de vida, de investigación y de ser, debido a los grandes cambios sociales, tecnológicos y ambientales actuales. En la educación básica, la educación ambiental es la encargada de conscientizar, preparar y promover en las y los estudiantes un sentido crítico de la naturaleza y de todo lo que conlleva. Esta investigación informa sobre el papel de la educación ambiental en el plan y programas de estudio, desde las acciones y durante la epidemia de Covid-19. Mediante dos entrevistas semiestructuradas virtuales en busca de un análisis bibliográfico, se reflexiona sobre la educación ambiental en educación básica, específicamente en el nivel primaria. En los resultados se encontró una realidad educativa en la que existe un distanciamiento entre lo esperado y lo realizado en torno a una conciencia ambiental.
\end{abstract}

Palabras clave: ambiente - educación - educación ambiental.

\begin{abstract}
Environmental education has emerged with force since the end of the 20th century as a paradigm of life, research and being, due to the great social, technological and environmental changes of our times. In basic education, environmental education is responsible for raising awareness, preparing and promoting in students a critical sense of nature and all that it entails. This research reports on the role of environmental education in the curricula, including the actions taken and the arrival of the COVID-19 pandemic. Through two semi-structured online interviews and bibliographic analysis, we reflect on environmental education in basic education, specifically at the primary level. Among our findings is an educational reality in which there is a gap between what is expected and what has been done to create an environmental awareness.
\end{abstract}

Keywords: environment - education - environmental education.

\footnotetext{
* Licenciada en Educación Especial, maestrante en Estudios Sociales y Culturales. Líneas de investigación: Educación, estudios sociales, niñez, grupos vulnerables. Universidad de Guanajuato. México. karenjaimes.kljm@gmail.com
} 


\section{Introducción}

El vínculo entre la naturaleza y el ser humano ha existido a lo largo de la historia de la humanidad, y se presenta en diversas situaciones que van desde una relación de respeto y armonía hasta la explotación y destrucción de ecosistemas a nivel global. En la actualidad, la preservación de la naturaleza es una de las principales necesidades sociales, debido a su exponencial deterioro causado por la mano del ser humano (Calixto, 2012; Pineda et al., 2018).

Tal como menciona Leff (2010), en la década de los años sesenta, debido a la irrupción de movimientos sociales y contraculturales, a la explosión poblacional y a la alarma ecológica, la mirada global comienza a enfocarse en el ambiente; empieza a percibirse la crisis ambiental y se cuestionan las prácticas que la han propiciado. Ahora, la relación entre naturaleza y sociedad se encuentra bajo constantes debates y en diversos escenarios, entre los que destacan el económico, político, académico, cultural, social y educativo, que de manera aislada o en conjunto analizan el deterioro de la naturaleza y, con ello, sus causas, consecuencias y soluciones.

Entre estos escenarios encontramos el educativo, que resulta de suma importancia para analizar las estrategias que surgen en la educación sobre la preocupación por la naturaleza. En México, de acuerdo con la Secretaría de Educación Pública (SEP, 2012: 2), "la mejor vía para construir un modelo de desarrollo alternativo, capaz de combatir el acelerado deterioro ambiental, la pérdida de recursos naturales, el cambio climático, la creciente desigualdad social, entre otros fenómenos que caracterizan nuestra época, es la educación". Por lo anterior, resulta imperativo hablar de una educación ambiental que se relacione con los retos sociales, ambientales, económicos y culturales, que plantean las sociedades, para lograr estrategias y experiencias exitosas en las que se pueda dar una resignificación entre naturaleza y ser humano.

En palabras de Calixto (2012), la educación ambiental propone, mediante diversas estrategias pedagógicas, contribuir a la formación de una conciencia sobre la responsabilidad del género humano en la relación con la vida en el planeta, a partir de la formación de sujetos críticos y participativos en situaciones ambientales. La educación ambiental cuenta con distintos actores sociales involucrados tanto de manera teórica como práctica, y un espacio social, como es la escuela, donde se realiza la formación de seres humanos con capacidad de empatía, respeto y amor a la naturaleza (UNESCO, 2019).

A lo largo de los años, México ha incluido en el plan y programas de educación básica (preescolar, primaria y secundaria) diversos contenidos y asignaturas que tienen como objetivo que los educandos adquieran una base conceptual para explicarse el mundo en que viven, y desarrollen habilidades para comprender y analizar los problemas sociales y ambientales tan diversos que se suscitan actualmente, para que lleguen a ser personas analíticas, críticas y responsables, aprendan a convivir con los demás y a reflexionar acerca del impacto que tienen sus acciones en la naturaleza, con el fin de que tomen una postura responsable y participativa con su entorno; sin embargo, con el paso del tiempo también han surgido interrogantes que cues- 
tionan si realmente en las escuelas de educación básica se realizan prácticas sobre educación ambiental, o si se quedan al margen realizando únicamente actividades dentro del aula, sin lograr una conscientización real de niñas, niños y jóvenes que lleven a la prácticas sus saberes ambientales en la vida escolar y en su vida cotidiana (Terrón, 2004; Morin, Delgado, 2016; SEP, 2017; Terrón, 2019).

A lo largo de estas décadas son claros los logros, pero también las dificultades que la educación ambiental ha tenido en el marco curricular nacional. Para Terrón (2019), la educación ambiental en los programas de estudio nacionales se encuentra en un círculo vicioso que impide lograr una formación de calidad, respeto y crítica, al detectar, por una parte, el aumento de contenidos ambientales en los libros de texto y, por otra, al considerar que en estos predomina la desarticulación entre los escenarios político, económico, cultural y social. Asimismo, los profesores se consideran poco capacitados para abordar temas ambientales: se remiten únicamente a las ciencias naturales o físicas y, en la práctica, los procedimientos no incitan al pensamiento crítico; existe poca relación con el contexto inmediato, por mencionar algunos aspectos.

De acuerdo con Pineda et al. (2018), el sistema educativo nacional requiere flexibilizar el plan de estudios, principalmente en la educación ambiental, adaptándolo a la realidad de cada individuo y su contexto. Aunque a nivel nacional la incorporación de la educación ambiental al marco curricular inicia en la década de los ochenta, y desde entonces ha estado sujeta a modificaciones, adaptaciones y cambios para atender las demandas contextuales y temporales, actualmente son claros los retos e inconsistencias entre la teoría y la práctica, vinculados con los métodos de enseñanza de la educación ambiental en el nivel básico, que aún se basa en un aprendizaje receptivo y pasivo, y cuayo desafío es centrarse en una educación ambiental desde la formación de actitudes, valores, participación y crítica social de los estudiantes. En relación con lo anterior, Calixto (2015: 19) propone que, en México, "para superar los problemas, consolidar los avances y enfrentar los retos, es necesario vincular la educación ambiental con el fomento de valores, con base en el conocimiento del origen y efectos de los problemas ambientales locales, regionales, estatales y globales".

Pero la educación ambiental va más allá de los centros escolares, es imprescindible formar una sociedad consciente de que es parte del problema y exija la implementación y desarrollo de políticas públicas que induzcan a dar a conocer la problemática ambiental, sus causas y probables consecuencias, en un mundo tan cambiante. Asimismo, la educación ambiental fortalece valores y comportamientos que impulsan la justicia social, el respeto por las diferentes formas de vida, etnias, credos, razas, entre otras, para alcanzar una sociedad equilibrada e interdependiente (Zabala, García, 2008).

La situación trastoca todos los rincones del mundo, los convierte en escenarios que presentan múltiples preocupaciones ambientales, de salud y sociales, debido al incremento de la industria, el deterioro del clima y los índices de contaminación, entre otros aspectos. Estos fenó- 
menos nos invitan a reflexionar y poner la mirada sobre acciones educativas desde la educación ambiental. Situaciones que han provocado la pandemia por Covid-19, una de las consecuencias que el capitalismo trae consigo debido al gran daño ambiental que produce y resulta en cambios de las dinámicas en todos los entornos (Gómez, 2020).

A raíz de la pandemia se generaron diversas medidas de control, como son: el cierre parcial o total de las actividades económicas, la reducción en las actividades gubernamentales, el confinamiento y distanciamiento social, el cierre de las escuelas, que han llevado a la sociedad a un proceso de adaptación a esta nueva realidad (OIT/CEPAL, 2020). La educación ambiental se encuentra ante estos procesos de adaptación, lo que ha generado nuevas aproximaciones ante este contexto, en el que sin duda el tema del medio ambiente está sobre la mesa, y plantea escenarios tanto positivos como negativos para su enseñanza.

La reflexión sobre la relación entre Covid-19 y educación ambiental permite tener un posible panorama ante esta nueva realidad, para identificar estrategias, retos y proyecciones a futuro que la educación, y en específico la educación ambiental, podría sugerir para hacer frente a esta situación en la que, sin duda, la causa ha sido la relación entre el ser humano y la naturaleza.

\section{Metodología}

La presente investigación parte del objetivo de analizar el papel de la educación ambiental en la vida escolar en nivel primaria de educación básica; se realizó desde un enfoque metodológico cualitativo, en el cual, de acuerdo con Rábajo (2011), se pretende dar cuenta de significados, vivencias, acciones e interacciones cotidianas de diversos sujetos observados en un determinado contexto. Se llevó a cabo mediante entrevistas semiestructuradas y en modalidad virtual. La entrevista, tal como mencionan Díaz et al. (2013: 163), "es una técnica de gran utilidad en la investigación cualitativa para recabar datos. Se define como una conversación que se propone un fin determinado distinto al simple hecho de conversar". Se optó por la modalidad virtual como estrategia para recabar información de agentes sociales que participan en el día a día en el escenario de la educación básica en México, debido a que la contingencia sanitaria impedía que fuese presencial. Se utilizó una muestra a conveniencia formada por aquellos casos disponibles a los cuales podemos tener acceso (Hernández et al. 2014). Se realizaron dos entrevistas a docentes de nivel primaria durante el primer semestre de 2020 (véase Tabla 1).

Tabla 1. Participantes de las entrevistas

\begin{tabular}{|c|l|l|l|}
\hline Participante & Sexo & Tipo de escuela & Antigüedad \\
\hline 1 & Mujer & Primaria, urbana & 8 años \\
\hline 2 & Mujer & Primaria, urbana & 20 años \\
\hline
\end{tabular}

Fuente: elaboración propia. 
El eje de interés versó sobre las acciones que realizan respecto a educación ambiental en la cotidianidad de la vida escolar en nivel primaria, siguiendo un enfoque de análisis de discurso mediante la modalidad de análisis por racimo, aplicable para estudios escritos y de exposiciones orales donde se expresen ideas o se discuta sobre temas específicos (Bermúdez, 1986). Se localizaron núcleos de referencia, tales son: plan y programas de educación primaria, acciones educativas sobre educación ambiental y la llegada de la pandemia por Covid-19, los cuales permitieron conjuntar críticamente la información teórica con la obtenida a través de las entrevistas.

\section{Desarrollo}

\section{La educación ambiental}

A partir de la década de los sesenta comienza la preocupación por el naturaleza, la cual se manifiesta en la implementación de políticas y medidas para regular el uso de patrimonios naturales en distintos escenarios, como son el educativo, cultural, político y económico, con el fin de frenar la crisis ambiental generada por el impacto de las acciones humanas; es a partir de entonces que comienzan a ser notorios nuevos conceptos como el de la educación ambiental (Barraza, Ceja, 2011).

En la actualidad, hablar de educación ambiental es relativamente común, está relacionado con términos como ecología, naturaleza, ambiente, educación, formación, por mencionar algunos; no obstante, la educación ambiental se encuentra en constante evolución y desarrollo, debido a los cambios sociales y naturales que acontecen, y que llevan a la reconfiguración y restructuración de paradigmas sobre la naturaleza y la sociedad.

De acuerdo con Zabala y García (2008), el término educación ambiental fue utilizado por primera vez durante la Conferencia Internacional sobre el Medio Ambiente en el año 1972 en Estocolmo; desde entonces se ha utilizado para lo referente a conocimientos, valores y actitudes que permitan acciones para enfrentar la crisis ambiental del mundo, con el objetivo de alcanzar una mejor calidad de vida. Sin embargo, darle un significado único a este término resulta complicado ya que dependerá del escenario y el momento en que es abordado, aunado a características o intereses sociales, culturales, políticos y económicos. Enseguida se muestran algunas definiciones sobre educación ambiental.

Según la Declaración de Tbilisi, de 1977, la educación ambiental debería constituir una educación permanente general que reaccione a los cambios que se producen en un mundo en rápida evolución. Esta educación debería preparar al individuo para tener una mayor comprensión de los principales problemas del mundo, mediante conocimientos técnicos y cualidades necesarias para desempeñar una función productiva, con el objetivo de mejorar la vida y proteger el medio ambiente (García, Priotto, 2009).

Para la Secretaría del Medio Ambiente y Recursos Naturales (SEMARNAT, 2016), la educación ambiental se refiere a un nuevo enfoque pedagógico, es un proceso que forma al individuo para 
desarrollar valores, conceptos y habilidades para desempeñar un papel crítico que le permita analizar la problemática ambiental y conocer su relación con la sociedad, para lograr una convivencia armónica entre los seres humanos, su cultura y su medio ambiente.

De acuerdo con Sauvé (2013), la educación ambiental debe actuar en conjunto con las dinámicas sociales contemporáneas, aquellos movimientos sociales y ciudadanías conscientes de los lazos indisociables entre las realidades sociales y ambientales que reivindiquen el bien común. Para esta autora, el ambiente se encuentra dentro de una realidad cultural y contextual determinada, lo que encamina a definiciones imprecisas y parciales.

La educación ambiental es un proceso que permite generar propuestas de solución a los problemas ambientales en la interacción con diversos actores sociales, a fin de compartir estrategias de solución que lleven a una toma de conciencia para el bienestar social y natural; la educación ambiental debe ser coherente entre la teoría y la acción, para que realmente se puedan lograr cambios sociales y ambientales, adecuados a los contextos y momentos requeridos (Terrón, 2004).

La importancia y el impacto de la educación ambiental radica en su dinamismo y en su diversidad para enfrentar la crisis medioambiental, por lo que cuenta con una gran variedad de actores sociales; García y Priotto (2009) reconocen el papel del personal de gobierno, del sistema educativo, consejos profesionales, guardaparques, activistas, grupos religiosos, promotores ambientales, entre otros, que actúan en conjunto para el bienestar ambiental, social y cultural.

En América Latina, la educación ambiental se compagina con el pensamiento de Paulo Freire, quien la plantea como una articulación con los movimientos comprometidos con cambios sociales, económicos, culturales y políticos desde la educación. Por su carácter social y político, permite una toma de conciencia basada en la libertad, un método pedagógico que procura dar al ser humano la oportunidad de redescubrirse al asumir reflexivamente el propio proceso en que se va descubriendo, manifestando y configurando (Freire, 1992), por lo que la educación ambiental, a partir de sus acciones, permite la transformación de la realidad al recuperar la conciencia y manifestarse en relaciones armónicas entre naturaleza y ser humano. Es para los fines de la presente investigación que se analizará la educación ambiental en relación con la educación básica, en específico el nivel primaria.

\section{La educación ambiental en la educación básica}

En México, la década de los ochenta marca el inicio formal de la implementación de políticas encaminadas a la educación ambiental, a partir de la colaboración de distintas secretarías, dependencias, universidades, con el fin de realizar investigaciones, proyectos y materiales sobre temáticas referentes a la problemática ambiental.

A la par, en 1986, durante el sexenio de Miguel de la Madrid, se emitió el decreto que establece que el tema de la ecología se integre al Sistema Educativo Nacional, con el objetivo de ini- 
ciar una pedagogía ecológica formal a nivel nacional con los siguiente postulados: $a$ ) introducir la materia de ecología en el plan de estudio de los maestros, $b$ ) incorporar contenidos educativos de temas ecológicos en los libros de texto de los diferentes niveles, c) realizar programas de capacitación para el magisterio, y d) propiciar que el servicio social de las licenciaturas se oriente a temas ecológicos (Amador et al., 2019: 18).

Pero, a pesar de que el tema de educación ambiental se incorporó desde hace aproximadamente cuatro décadas a los planes de estudio, a lo largo de los años se han observado distintas dificultades y problemáticas en cuanto a la aplicación efectiva de los contenidos y prácticas en la educación básica. Lo cual ha conducido a modificar, restablecer y adoptar nuevas estrategias para cumplir con las demandas que surgen en relación con la naturaleza y la sociedad. Covas (2004) propone tres enfoques para abordar la dimensión ambiental en el proceso educativo, en los que la educación y la escuela son el medio para desarrollar la capacidad de observación, comprensión y responsabilidad para una adecuada interpretación del mundo y una actuación social consecuente a las necesidades y exigencias de la realidad actual.

- Enfoque comunitario: el objetivo de este enfoque es la contextualización del contenido al medio ambiente donde vive el estudiante, parte de la solución de los problemas cercanos, del contexto, ubicando a los estudiantes en las realidades ambientales locales, luego a las regionales y después a las globales.

- Enfoque sistémico: la autora hace mención sobre la constitución sistémica del medio ambiente; esto significa entenderlo como un todo, compuesto por partes que interactúan entre sí, de tal forma que un cambio que se produzca en alguno tendrá impactos en los demás.

- Enfoque interdisciplinario: este enfoque representa el conjunto de disciplinas y su interacción constante a fin de que no se produzca de manera aislada o dispersa, se trata de permitir una toma de conciencia y con ello, de la articulación de diferentes disciplinas para comprender un suceso y avanzar hacia su análisis y solución a partir de múltiples disciplinas.

Tomando los enfoques propuestos por Covas (2004) como ejes de un proceso pedagógico orientado a la educación ambiental y conjuntándolos con las problemáticas mencionadas anteriormente, el sistema educativo mexicano enfrenta grandes retos que enfrentar para garantizar la responsabilidad con, para y desde la naturaleza.

\section{La educación ambiental en el nivel primaria, plan de estudio y actores sociales}

El plan y programas de estudio de educación básica presentan el conjunto de objetivos, contenidos, criterios metodológicos y técnicas de evaluación que orientan el quehacer académico, y 
marcan las pautas en la educación desde el nivel preescolar hasta la secundaria. Para fines de esta investigación, se analiza el libro Aprendizajes clave para la educación integral. Plan y Programas de Estudio para la Educación Básica (SEP, 2017), que pone un mayor énfasis en el nivel de primaria.

El plan de estudio hace mención de algunas características del perfil de egreso, refiriéndose a los rasgos que los estudiantes deberán adquirir en cada nivel; se encuentra organizado por 11 ámbitos, dentro de los cuales se mencionan dos que se articulan con los fines planteados en la educación ambiental, sin prescindir de la importancia de los otros ámbitos, al contrario, pensando en su acción conjunta. Los ámbitos relacionados con la educación ambiental son:

- Exploración y comprensión del mundo natural y social: que los educandos reconozcan algunos fenómenos naturales y sociales que le generan curiosidad y necesidad de responder preguntas. Los explore mediante la indagación, el análisis y la experimentación.

- Cuidado del medio ambiente: que los educandos, reconozcan la importancia del cuidado del medio ambiente, identifiquen problemas locales y globales, así como soluciones que pueden poner en práctica, por ejemplo, apagar la luz y no desperdiciar el agua (SEP, 2017).

Aunado a estas características de egreso, se incluyen a continuación dos rasgos que también están considerados:

- Gusta de explorar y comprender el mundo natural y social: identifica una variedad de fenómenos del mundo natural y social, lee acerca de ellos, se informa en distintas fuentes, indaga aplicando principios del escepticismo informado, formula preguntas de complejidad creciente, realiza análisis y experimentos. Sistematiza sus hallazgos, construye respuestas a sus preguntas y emplea modelos para representar los fenómenos. Comprende la relevancia de las ciencias naturales y sociales.

- Muestra responsabilidad por el ambiente: promueve el cuidado del medio ambiente de forma activa. Identifica problemas relacionados con el cuidado de los ecosistemas y las soluciones que impliquen la utilización de los recursos naturales con responsabilidad y racionalidad. Se compromete con la aplicación de acciones sustentables en su entorno (SEP, 2017: 97).

El plan de estudio plantea la organización de sus contenidos en tres componentes curriculares, dentro de los cuales se encuentran los Campos de Formación Académica, organizados a su vez en tres subcampos: Lenguaje y comunicación; Pensamiento matemático; y Exploración y comprensión del mundo natural y social, cada uno organizado en asignaturas. 
El campo de formación académica de interés para la presente investigación es el de exploración y comprensión del mundo natural y social. Este campo está formado por enfoques de distintas disciplinas de las ciencias sociales: biología, física y química, y abarca aspectos sociales, políticos, económicos, culturales y éticos. Uno de los principales objetivos de este campo es que los alumnos adquieran una base conceptual para explicarse el mundo en que viven, que desarrollen habilidades para comprender y analizar problemas diversos y complejos con un pensamiento analítico, crítico, participativo y responsable.

Otro aspecto a considerar es la participación de actores sociales en la puesta en marcha de acciones sobre educación ambiental. Los docentes son los encargados de trasmitir, enseñar y conscientizar, a partir de sus capacidades y su experiencia, el logro de aprendizajes a niñas, niños y jóvenes, según lo plasmado en el plan y programas de estudio; su participación es de gran importancia para comprender y analizar los retos por los que atraviesan al realizar o no prácticas de educación ambiental en la cotidianidad escolar, ya que, como mencionan Espejel et al. (2012: 332), "el docente es un facilitador activo en todo momento del proceso educativo ambiental, el maestro debe convertirse también en animador, es decir, en persona que ayude a los estudiantes a descubrir y a utilizar su potencial para trabajar problemas ambientales".

Pero también es importante considerar a las niñas y niños como actores sociales de las prácticas educativas ambientales, pensando en su importante participación como protagonistas de la sociedad, tanto en la actualidad como en el futuro. De acuerdo con Pavez (2012: 81), se ve a las niñas y niños como actores sociales que participan de diversas maneras en la vida social, aunque de forma diferente a las personas adultas.

Recientemente, se ha observado la participación de la niñez en distintos ámbitos desde posturas que surgen del paradigma ecosociocéntrico, en el que la vida humana y la satisfacción de necesidades reconocen los ecosistemas y la necesidad de respetarlos, así como la reparación y compensación por el uso de la naturaleza (Pimentel, 2014); demuestran un mayor respeto, sensibilidad y amor al mundo, a la vida y a los seres vivos, en la comprensión de que ningún ser vivo es más importante que otro, situación que ha llevado a replantear los paradigmas antropocéntricos y adultocéntrico; el primero de estos paradigmas plantea que la naturaleza tiene un valor extrínseco al ser humano, refiriéndose a todo lo que le puede dar (Suarez et al., 2007; Macías, 2017); mientras que el segundo paradigma se refiere a la existencia de una relación asimétrica entre adultos y niñez, donde los adultos son el modelo, el parámetro y la meta a alcanzar cuando el niño sea adulto, para ejercer la dominación (Hecht, 2013; Pusseto, 2016), colocando a niñas y niños en situaciones de subordinación en diversos ámbitos de la sociedad. No obstante, la emergente participación de la niñez es notoria, contradiciendo los paradigmas anteriormente mencionados, como es el caso de la adolescente sueca Greta Thunberg, quien durante 2018 realizó una huelga escolar en protesta por el cambio climático, que ha derivado en un movimiento activista sobre los problemas del calentamiento global, al que se le han unido cientos de niños y niñas, jóvenes y adultos. 
En las escuelas, los actores sociales que realizan acciones sobre educación ambiental regularmente son los docentes, niñas y niños, padres de familia o comunidades, principalmente en zonas rurales, donde se percibe una poca o nula participación de expertos en temas ambientales para brindar talleres o cursos que permitan generar estrategias para un mundo y una vida mejor, a pesar de que en esos centros educativos se encuentran los actores claves para el futuro de la sociedad (Espejel et al., 2012; Pineda et al., 2018).

\section{La educación ambiental ante el Covid-19}

A inicios de 2020, el mundo se encontró ante una situación que modificaría por completo las dinámicas sociales, económicas, culturales y ambientales, lo cual, en palabras de Leff (2010), permite cuestionar no sólo la creencia de la supremacía del hombre sobre los demás seres vivos y el derecho a dominar y explotar la naturaleza en beneficio del "hombre" sino, además, el sentido mismo de la existencia humana, fincada en el crecimiento económico y el progreso tecnológico, por sobre gran parte de la sociedad y de la naturaleza.

El motivo de esta crisis fue la aparición del coronavirus SARS-CoV2 en China, a finales de diciembre de 2019, el cual provoca una enfermedad llamada Covid-19. Los coronavirus son una familia de virus que causan enfermedades que van desde el resfriado común hasta enfermedades respiratorias más graves que pueden conducir a la muerte; lo particular del Covid-19 ha sido su exponencial propagación y el desconocimiento por parte de la comunidad médica sobre los síntomas y el tratamiento, debido a su novedad, lo cual indujo a su expansión por todo el mundo, por lo que la Organización Mundial de la Salud ${ }^{1}$ la declaró una pandemia global y para contenerla se implementaron acciones como el autoaislamiento, la cuarentena y el distanciamiento social.

Evidentemente, ante la pandemia de Covid-19, en el mundo se han presentado diversos efectos, tanto positivos como negativos, en ámbitos que van desde lo económico, social y ambiental que han impactado notablemente en la sociedad. La situación económica muestra un lado negativo, sobre todo en países del sur, en los cuales las desigualdades son incuestionables: el desempleo, la suspensión de actividades, la dificultad de acceso a sistemas de salud, muestran un panorama desalentador. Por otro lado, la situación ambiental se visualiza con efectos positivos pues pareciera que la naturaleza se está tomando un respiro al disminuir la actividad humana, que ha sido notorio en China y Europa debido a la disminución de gases de efecto invernadero, una menor contaminación atmosférica que se ha visto reflejada en la presencia de animales en distintas áreas, entre otros aspectos.

No obstante, el impacto va más allá de estos aspectos y se relaciona con múltiples ámbitos de la vida; esta crisis da la oportunidad a la sociedad de pensar sobre las decisiones y hábitos cotidianos. Es entonces que la educación ambiental juega un papel de gran importancia ante

1 Información obtenida de https://coronavirus.gob.mx/covid-19/ página oficial del Gobierno de México. 
la prevención, la modificación y la transformación de hábitos sociales que impactan en el ambiente, tales como los alimentos, medios de transporte, el respeto a los animales y las plantas, entre otros, donde las escuelas de educación básica son uno de los principales medios de conscientización al impartir una educación ambiental reflexiva y valiosa, impulsada por gobiernos, centros educativos y la sociedad.

Con la llegada del Covid-19, el aislamiento, la cuarentena y el distanciamiento social han sido los ejes rectores para evitar la diseminación del virus, situación que trastoca el ámbito de la educación al trasladar los espacios educativos a la educación virtual o a distancia; en México, principalmente mediante el programa televisivo llamado "Aprende en Casa", plataformas digitales y mensajería instantánea (Rivero, Bahena, 2021), aunado a otras estrategias, con el fin de evitar una mayor brecha educativa debido a las desigualdades sociales, económicas, tecnológicas y educativas en el país.

De la misma manera, la educación ambiental también entró en la transición de la presencialidad a la virtualidad. En Latinoamérica, ante el contexto de pandemia, los temas ambientales se han retomado de distintas maneras; con la modalidad a distancia se encuentran trabajos interdisciplinarios y transversales sobre aprendizaje situado con el tema de quemas de pastizales, con el objetivo de desarrollar un pensamiento desde las problemáticas ambientales, económicas y sociales de la región (Gómez, 2020); otros estudios se orientan a la elaboración de una propuesta pedagógico-didáctica aplicable a la enseñanza virtual, para abordar los contenidos de educación ambiental y biología con la intervención de estudiantes y docentes, que permiten una aproximación interdisciplinar y contextual a la realidad (Genovese et al., 2020). También se encuentra un estudio acerca del desarrollo de un proyecto sobre competencias STEAM (ambientales, tecnológicas, pedagógicas y artísticas), a partir de prácticas experimentales en casa con semillas, que ha logrado la interacción de los estudiantes con sus familias (García et al., 2021).

La existencia de diversas propuestas y estrategias para implementar la educación ambiental a distancia demuestra su importancia ante un contexto como el actual, la acción es permanente ante situaciones sociales, de salud, ambientales y económicas como las derivadas de la pandemia. El panorama en América Latina muestra diversas estrategias que permiten, a estudiantes, docentes y personal interesado en temas ambientales, reflexionar sobre el papel de la enseñanza en la educación ambiental para romper con paradigmas que han llevado a consecuencias devastadoras a nivel mundial.

\section{Resultados}

A partir de la revisión documental y bibliográfica, así como de las entrevistas semiestructuradas realizadas en modalidad virtual, el panorama sobre la educación ambiental invita a su uso eficaz y pertinente en la sociedad como una estrategia de auxilio a las crisis socioambientales que acontecen. Darle a esta disciplina la importancia que merece nos colocará en mejores es- 
cenarios sociales, que aporten una visión más crítica, reflexión y solución a situaciones sociales, ambientales y económicas.

La importancia de la educación ambiental en el nivel de la educación básica se puede visualizar en los rasgos mencionados en el perfil de egreso de nivel primaria, pues para lograrlo es necesario llevar a cabo de forma gradual prácticas y reflexiones en torno al medio ambiente, impulsando a niñas y niños al conocimiento del medio natural y social y el cuidado de la naturaleza a partir de un pensamiento crítico y responsable. Enseguida se muestran dos fragmentos de las entrevistas realizadas:

Considero que al fomentar acciones de educación ambiental los niños encuentran la felicidad en los detalles sencillos y no en el consumismo, que al final del ciclo del sistema capitalista va destruyendo nuestro planeta (participante 1).

Las actividades de ciencias naturales o las que tiene que ver con el medio ambiente sensibilizan a los niños a que cuiden su entorno, a los animalitos, la contaminación, lo malo es que los tiempos escolares son cortos y no se pueden hacer muchas actividades sobre eso (participante 2).

En el análisis del plan de estudio se encontraron las asignaturas relacionadas con la educación ambiental en primaria, con sus respectivos propósitos (Tabla 2): 
Tabla 2. Asignaturas con propósitos relacionados con la educación ambiental

\begin{tabular}{|c|c|}
\hline Conocimiento del medio & Historia, paisajes y convivencia en mi localidad \\
\hline $\begin{array}{l}\text { - Desarrollar la curiosidad e interés por explorar } \\
\text { las características naturales y sociales de su entor- } \\
\text { no y sus cambios en el tiempo. } \\
\text { - Comprender la importancia de las reglas para la } \\
\text { convivencia y asumir una postura respetuosa ante } \\
\text { la diversidad natural y cultural del lugar donde vi- } \\
\text { ven. } \\
\text { - Proponer medidas de prevención y cuidado a par- } \\
\text { tir de identificar el impacto que tienen sus accio- } \\
\text { nes en sí mismos, en los demás y en el medioam- } \\
\text { biente. }\end{array}$ & $\begin{array}{l}\text { - Explorar el entorno, la vida cotidiana y la conviven- } \\
\text { cia, para reconocer sus características en el presente } \\
\text { e indagar sus cambios con el paso del tiempo. } \\
\text { - Comprender que sus acciones y las de otros tienen } \\
\text { impacto en el medioambiente para asumir una pos- } \\
\text { tura responsable y participar de manera activa en su } \\
\text { cuidado. } \\
\text { - Desarrollar su identidad y sentido de pertenencia } \\
\text { mediante la valoración de la diversidad natural y } \\
\text { cultural de su entorno. }\end{array}$ \\
\hline Ciencias naturales y tecnología & \\
\hline $\begin{array}{l}\text { - Comprender que los mundos físico y biológico } \\
\text { cambian con el tiempo, debido a interacciones na- } \\
\text { turales y a la acción de los seres humanos. } \\
\text { - Conocer y distinguir los componentes biológicos } \\
\text { y físicos de los ecosistemas, y desarrollar una acti- } \\
\text { tud crítica sobre las acciones que pueden provocar } \\
\text { su deterioro. } \\
\text { - Integrar y aplicar saberes para hallar opciones de } \\
\text { intervención en situaciones problemáticas de su } \\
\text { contexto cercano, asociadas a la ciencia y la tec- } \\
\text { nología. }\end{array}$ & $\begin{array}{l}\text { - Obtener, representar e interpretar información } \\
\text { geográfica en la escala local, regional, nacional y } \\
\text { mundial. } \\
\text { - Reconocer la diversidad natural y cultural del espa- } \\
\text { cio geográfico, para fortalecer su identidad y condu- } \\
\text { cirse con respeto ante las diferentes formas de vida } \\
\text { y culturas. } \\
\text { - Explicar relaciones entre las actividades en dife- } \\
\text { rentes regiones del mundo, para desenvolverse con } \\
\text { un sentido de responsabilidad respecto al cuidado } \\
\text { de los recursos naturales. }\end{array}$ \\
\hline Historia & Formación cívica y ética \\
\hline $\begin{array}{l}\text { - Relacionar acontecimientos del presente con el } \\
\text { pasado para comprender la sociedad. } \\
\text { - Reconocer la importancia de comprender al otro } \\
\text { para fomentar el respeto a la diversidad cultural a } \\
\text { lo largo del tiempo. } \\
\text { - Reconocer que valorar y cuidar el patrimonio na- } \\
\text { tural y cultural fortalece la identidad. }\end{array}$ & $\begin{array}{l}\text { - Fortalecer la identidad personal y colectiva a partir } \\
\text { de su reconocimiento. } \\
\text { - Reconocer que la pertenencia a distintos grupos } \\
\text { sociales, caracterizados por su diversidad, contri- } \\
\text { buye a la conformación de la identidad y promueve } \\
\text { relaciones empáticas, equitativas, interculturales y } \\
\text { libres de discriminación. }\end{array}$ \\
\hline
\end{tabular}

Fuente: Elaboración propia con base en SEP (2017).

No obstante, el personal docente entrevistado considera que únicamente retoma la asignatura de ciencias naturales para realizar actividades de educación ambiental, cree también que existe una organización aislada de las temáticas, lo cual dificulta la realización de actividades de manera integral sobre temas de educación ambiental (participantes 1 y 2).

Pese a que dentro del plan de estudio no se encuentra desarrollado el concepto de educación ambiental como tal, se puede observar que sí existen contenidos para abordar lo referente al tema en el Campo de Formación, Exploración y Comprensión del Mundo Natural y Social; no obstante, es importante analizar cómo es que se imparten dichos contenidos en las aulas, si existen prácticas escolares o si únicamente forman parte del libro Aprendizajes clave para la educación integral, así como de los discursos políticos, académicos y sociales sobre educación ambiental. 
Pienso que hay temas que dan para reflexionar mucho, ahí podría entrar la creatividad del docente para desarrollar actividades y recursos que le permitan conscientizar (participante 1).

Es entonces que las entrevistas realizadas permiten una aproximación al panorama de la realidad sobre las acciones que se llevan a cabo en relación con la educación ambiental en el día a día. Dentro de la escuela se han llevado a práctica los siguiente temas sobre educación ambiental:

El cuidado de árboles; cuidado del agua; reciclaje de materiales para hacer manualidades; depositar basura en su lugar; regar plantas del aula o de la escuela (participante 1).

Reciclaje; cuidado de las plantas; separación de residuos; contaminación; uso de PET para manualidades (participante 2).

Las prácticas sobre educación ambiental son escasas, si tomamos en cuenta que se realizan a lo largo de un ciclo escolar, además de que no presentan una gran diversidad; esto puede deberse tanto a cuestiones de tiempo, creatividad, falta de recursos económicos, entre otras cosas, provocando un alejamiento de las experiencias ambientales de la niñez y del mismo personal docente. A partir de la revisión documental y de las entrevistas realizadas, es posible mencionar las siguientes dificultades en cuanto a la aplicación efectiva de contenidos y prácticas sobre educación ambiental en el nivel primaria:

- No existe una visión integral y coherente de los contenidos sobre la naturaleza.

- No se asume lo ambiental con perspectiva crítica que permita hacer una comprensión y denuncia de las causas de fondo con carácter político, económico, histórico y social acerca de las problemáticas ambientales.

- Prevalece una visión parcial y limitada tanto en su causa como en su solución.

- Los docentes reconocen que no se sienten capacitados para abordar de manera conveniente temas y proyectos ambientales.

- Existe poca apertura para dar capacitación o talleres sobre temas relacionados con la educación ambiental a los docentes de primaria.

- Existe poca vinculación en los libros de texto para alcanzar una visión integrada y compleja de la realidad.

- Existe poca o nula relación entre libros de texto y contextos escolares, principalmente en contextos rurales.

- Las prácticas escolares diarias respecto a temas ambientales son mínimas.

- Los temas se presentan de manera asilada entre asignaturas.

- Se le da una menor importancia en relación con otras asignaturas.

- Se priorizan los contenidos referentes a la vida urbana sobre la rural (Buendía, 2019; participantes 1 y 2 ). 
Para finalizar, en el plan de estudio sí existen temáticas relacionadas con la educación ambiental; sin embargo, también hay dificultades en la práctica cotidiana y reflexiva, lo cual induce a continuar patrones de educación que se encuentran distantes a las problemáticas sociales y ambientales, que viculen la toma de conciencia, responsabilidad y crítica de nuestros hábitos que puedan repercutir de manera positiva o negativa en dichas situaciones. Tal es el caso del momento actual, en el que el Covid-19 ha llegado para replantearnos nuestro hacer en el mundo.

La educación ambiental invita a reflexionar en la toma de decisiones ante contextos como los de ahora, causados por el Covid-19; tenemos que incentivar a los niños a nuevas prácticas y nuevas formas de ver el mundo, en el que seamos uno mismo, para evitar más catástrofes y daños colaterales que afectan a los seres vivos (participante 1).

\section{Discusión y conclusiones}

En México, de acuerdo con el plan y programas de estudio de educación básica, la educación ambiental pareciera una parte secundaria del entramado de asignaturas y actividades a cumplir al ser colocada en un espacio supletorio, lo cual lleva a la poca sensibilización, conciencia y crítica de prácticas ambientales en el marco de la cotidianidad en todos los actores sociales.

Uno de los aspectos de importancia al hablar de educación ambiental, es el uso oportuno del plan y programas de estudio, en el que sí existen diversas asignaturas con propósitos relacionados con la educación ambiental; no obstante, la falta de tiempo, creatividad y adaptabilidad, dificulta que se aprovechen en su totalidad, generando aprendizajes aislados, monótonos, teóricos y alejados de la realidad, lo cual se relaciona con las respuestas de las personas entrevistadas.

Además, la falta de capacitación para que maestros y maestras puedan trasmitir con claridad temas prácticos y reflexivos que generen realmente una conciencia social y ambiental. Amador et al. (2019: 21) mencionan "que existe la urgencia de que el gobierno en turno priorice este tema, y le destine tanto recursos económicos como humanos para su incorporación en las escuelas de todo el país".

A nivel primaria, se pueden observar algunas prácticas y acciones sobre educación ambiental, no obstante, son aisladas y escasas, por lo que se sugiere la realización de proyectos continuos sobre temáticas ambientales, la solicitud de talleres para el personal docente, la colaboración con actores del contexto cercano, con el fin de aumentar las experiencias ambientales de la comunidad escolar, lo cual se relaciona con lo mencionado por Calixto (2015) y Pineda et al. (2018): se requiere que el plan de estudios se adapte a las realidades de los contextos y se vincule con el fomento de valores.

El énfasis de la educación ambiental tendría que estar puesto en sus prácticas más que en su discurso; en momentos como los actuales, debido a la pandemia de Covid-19, su importan- 
cia es sin duda valorada, pero existe el temor de que se deje de lado cuando las cosas vuelvan a la cotidianidad o a la "nueva normalidad".

No obstante, la emergencia es notoria, la pandemia de Covid-19 ha llevado a la reflexión de estrategias ambientales en la cotidianidad, en la escuela, así como en otros escenarios; además, la niñez y la ciudadanía en general muestran interés en acciones ambientales, desde el comportamiento hasta los valores, tal como menciona Covas (2004: 6), "existe la necesidad de lograr en los educandos un aprendizaje que provoque en estos un cambio en el comportamiento y la resignificación de los valores", a fin de modificar las dinámicas sociales, educativas y ambientales para una mejora. La educación ambiental constituye entonces una manera de hacer frente a las crisis sociales y ambientales, primeramente, al dar cuenta de que el surgimiento de dicha crisis se encuentra vinculada a la relación que existe entre la naturaleza y el ser humano, seguido por la creación de estrategias didácticas que lleven a la reflexión y a la aplicabilidad en cada contexto.

Durante el periodo de su educación básica, la niñez se encuentra ávida de realizar prácticas ambientales. Los y las maestras, padres de familia, la comunidad y demás actores involucrados, tienen un gran reto: hacer que perdure el amor a la naturaleza, que logre mantenerse desde la niñez hasta la adultez, lo cual se puede conseguir a partir de darle la importancia que merecen dichos temas y prácticas en la cotidianidad escolar. Formar ciudadanos responsables, críticos y participativos en las dinámicas sociales, ambientales, políticas y culturales, y que no sean formados sólo como medios de producción, permite vislumbrar un futuro mejor para la sociedad y naturaleza.

\section{Referencias}

Amador, K.; M. Castillo; L. Muñoz; N. Vega (2019). Educación ambiental formal: el caso de la educación básica. Revista de Divulgación Científica, 19, 18-23.

Barraza, L.; M. Ceja (2011). La planeación y la realización de la educación ambiental. Temas sobre conservación de vertebrados silvestres en méxico, 351-372.

Bermúdez, M. (1986). Aplicación del análisis de contenido a la entrevista. Revista Ciencias Sociales, 33, 135-143.

Calixto, R. (2012). Investigación en educación ambiental. Revista Mexicana de Investigación Educativa, 17(55), 1019-1033. https://www.redalyc.org/pdf/140/14024273002.pdf

Calixto, R. (2015). Educación ambiental para la sustentabilidad en la educación secundaria. Actualidades Investigativas en Educación, 15(3), 1-22. https://doi.org/10.15517/aie.v15i3.20929

Covas, O. (2004). Educación ambiental a partir de tres enfoques: comunitario, sistémico e interdisciplinario. Revista Iberoamericana de Educación, 35(1), 1-7. https://doi.org/10.35362/ $\underline{\text { rie3512941 }}$ 
Díaz, L.; U. Torruco; M. Martínez; M. Varela (2013). La entrevista, recurso flexible y dinámico. Investigación en Educación Médica, 2(7), 162-167.https://doi.org/10.1016/s2007-5057(13)72706-6

Espejel, A.; A. Flores; I. Castillo (2012). La educación ambiental en el bachillerato: el caso de los docentes que imparten la materia de ecología, Puebla-Tlaxcala (México). Profesorado. Revista de Currículum y Formación de Profesorado, 16(3), 321-339.

Freire, P. (1992). Pedagogía de la esperanza: un reencuentro con la pedagogía del oprimido. Argentina: Siglo XXI Editores. https://redclade.org/wp-content/uploads/Pedagog\%C3\%ADa-dela-Esperanza.pdf

García, D.; G. Priotto (2009). Educación ambiental: aportes políticos y pedagógicos en la construcción del campo de la Educación Ambiental. Buenos Aires: Secretaría de Ambiente y Desarrollo Sustentable.

García, P.; L. Parada; J. Martín (2021). La educación ambiental, factor de cambio. Agricultura urbana en Teusaquillo, una experiencia educativa en medio de la pandemia. Colombia: Centro de Recursos para el Aprendizaje y la Investigación. Universidad Santo Tomás. https://repository. usta.edu.co/handle/11634/33992

Genovese, D.; A. Del Valle; C. Peñaloza (2020). Experiencia de Taller Integrador de profesorado de Biología en contexto de pandemia. Revista de Educación en Biología, 2(Extraordinario).

Gómez, C. (2020). El trabajo interdisciplinario a partir del abordaje de la Educación Ambiental en contexto situado. Revista de Educación en Biología, 2(Extraordinario).

Gomez, L. (2020). El desafío ambiental: enseñanzas a partir de la Covid-19. MEDISAN, 24(4), 1-16. http://scielo.sld.cu/pdf/san/v24n4/1029-3019-san-24-04-728.pdf

Hecht, A. (2013). Del adultocentrismo a la agencia infantil: un enfoque desde la socialización lingüística. Revista Infancias e Imágenes, 12(1), 7-17.

Hernández, R.; C. Fernández; P. Baptista (2014). Metodología de la investigación (6ª ed.). México: McGraw-Hill.

Leff, E. (2010). Discursos sustentables. México: Siglo XXI.

Macías, L. (2017). Niveles de ecocentrismo y antropocentrismo en estudiantes universitarios de ciencias ambientales. Revista Electrónica Formación y Calidad Educativa, 5(1), 123-133.

Morin, E.; C. Delgado (2016). Reinventar la educación. México: Multiversidad Mundo Real Edgar Morin.

OIT y CEPAL (2020). La pandemia por la Covid-19 podría incrementar el trabajo infantil en América Latina y el Caribe. Nota Técnica N ${ }^{\circ}$ 1. https://www.cepal.org/es/publicaciones/45679-la-pandemia-la-covid-19-podria-incrementar-trabajo-infantil-america-latina

Pavez, S. (2012). Sociología de la Infancia: las niñas y los niños como actores sociales. Revista de Sociología, (27), 81-102. https://revistadesociologia.uchile.cl/index.php/RDS/article/ view/27479 
Pimentel, B. (2014). Buen vivir y descolonialidad. Crítica al desarrollo y la racionalidad instrumentales. México: UNAM.

Pineda, C.; X. López; E. Wehncke; B. Maldonado (2018). Construir sociedades comprometidas con el entorno natural: educación ambiental en niños del sur de Morelos, México. Región y Sociedad, 30(72), 1-26. https://doi.org/10.22198/rys.2018.72.a896

Pussetto, M. (2016). Entre niñez, estado y adultocentrismo. Cercanías y distancias desde una práctica extensionista. Crítica y Resistencias. Revista de Conflictos Sociales Latinoamericanos, $2,188-205$.

Rábajo, J. (2011). Líneas de investigación cualitativa. México: Universidad de Guanajuato.

Rivero, E.; A. Bahena (2021). Interrelaciones socieducativas, educación en línea y bienestar durante el confinamiento. Revista Prisma Social, 33(2), 120-136.

Sauvé, L. (2013). Educación ambiental y ecociudadania. Dimensiones claves de un proyecto político-pedagógico. Revista Científica, 1(18), 12-23. https://doi.org/10.14483/23448350.5558

SEMARNAT (2016). Lineamientos para el otorgamiento de subsidios. "Hacia la igualdad y sustentabilidad ambiental". México: SEMARNAT. http://dgeiawf.semarnat.gob.mx:8080/ibi apps/ WFServlet?IBIF_ex=D1_R_EAMBIENT01_01\&IBIC_user=dgeia mce\&IBIC_pass=dgeia mce

SEP (2012). Educación ambiental para la sustentabilidad. México: Dirección General de Educación Superior para Profesionales de la Educación.

SEP (2017). Aprendizajes clave para la educación integral. Plan y programa de estudio para la educación básica. Primera Edición. México: SEP.

Suárez, E.;M.Salazar; B. Hernández; A. Martín (2007). ¿Qué motiva la valoración del medio ambiente? La relación del ecocentrismo y del antropocentrismo con la motivación interna y externa. Revista de Psicología Social, 22(3), 235-243. https://doi.org/10.1174/021347407782194434

Terrón, E. (2004). La educación ambiental en la educación básica, un proyecto inconcluso. Revista Latinoamericana de Estudios Educativos (México), XXXIV(4), 107-164. https://www.redalyc. org/pdf/270/27034404.pdf

Terrón, E. (2019). Esbozo de la educación ambiental en el currículum de educación básica en México. Una revisión retrospectiva de los planes y programas de estudio. Revista Latinoamericana de Estudios Educativos (México), XLIX(1), 315-346. https://www.redalyc.org/articulo.oa?id=27058155011

UNESCO (2019). La educación transforma vidas. Empoderar a las personas y garantizar la inclusión y la igualdad. https://www.buenosaires.iiep.unesco.org/es/publicaciones/la-educaciontransforma-vidas

Zabala, l.; M. García (2008). Historia de la Educación Ambiental desde su discusión y análisis en los congresos internacionales. Revista de Investigación, 32(63), 201-218. https://dialnet.unirioja.es/descarga/articulo/2547197.pdf 